OPEN ACCESS

Edited by:

Iccha Basnyat,

James Madison University,

United States

Reviewed by:

James Olumide Olufowote,

University of Oklahoma, United States

Isaac Nahon-Serfaty,

University of Ottawa, Canada

${ }^{*}$ Correspondence:

Allister Nelson

anelso26@gmu.edu

Specialty section

This article was submitted to Health Communication,

a section of the journal

Frontiers in Communication

Received: 07 January 2019

Accepted: 15 May 2019

Published: 31 May 2019

Citation:

Nelson A (2019) Ups and Downs: Social Media Advocacy of Bipolar Disorder on World Mental Health Day.

Front. Commun. 4:24.

doi: $10.3389 /$ fcomm.2019.00024

\section{Ups and Downs: Social Media Advocacy of Bipolar Disorder on World Mental Health Day}

\author{
Allister Nelson* \\ Department of Communication, George Mason University, Fairfax, VA, United States
}

Bipolar disorder is a serious illness that claims hundreds of lives each year. In a watershed movement as the framing of bipolar shifts, the disease is gaining more awareness after the diagnosis of Mariah Carey and advocacy by opinion leaders like Stephen Fry. Social media advocacy is a powerhouse that celebrities with bipolar disorder utilize each World Mental Health Day to reduce stigma and increase awareness of bipolar type 1, which constitutes highs of mania and lows of depression, bipolar type 2, which includes lower hypomania and depressions, alongside the less severe mood swings of cyclothymia. This study collected 160 celebrities' social media posts on Twitter that were shared on World Mental Health Day. It randomly sampled amongst the Tweets for thematic and content analysis to discover valences in positive and negative experiences of bipolar disorder and the framing of bipolar. To study effects of opinion leaders on the public, this random sample of opinion leaders was compared to a cumulative census sample of Twitter posts by the public. The public Tweets were gathered a month afterwards following the mental health hashtags \#bipolar and \#bipolardisorder. The findings of the study provide guidelines for opinion leaders to craft social media posts to increase positive framing of bipolar disorder via positively valenced, encouraging messages. The study lays out what messages resonate with the general public to reduce bipolar disorder stigma. This establishes a basis for further social media campaigns focused on positive, constructive messages that improve the well-being of bipolar individuals globally. The findings suggest that under Roger's diffusion of innovation theory, opinion leaders diagnosed with bipolar disorder are effectively shifting the dialogue surrounding mental health to one of stigma reduction and acceptance. Mainly positively valenced Tweets were shared about bipolar disorder in the general public Twitter sphere a month after opinion leaders communicated support, comfort and encouragement on World Mental Health Day under Burleson's inferable communication goal guidelines. The study suggests that consistent positive messaging about bipolar shared by opinion leaders will have a lasting positive frame shift toward mental health awareness if this trend continues.

Keywords: bipolar disorder, diffusion of innovation, World Mental Health Awareness Day, mental health, opinion leaders, Rowan's CAUSE model of risk communication 


\section{INTRODUCTION}

Bipolar disorder is an often maligned, highly misunderstood mental illness. From colloquialisms such as "the weather is bipolar" to accusations of women being "bipolar exes," we often view individuals with bipolar disorder as unstable, prone to violence and destructive tendencies, complete with unmanageable mood swings. But more often, individuals with bipolar disorder are likely to be victims of abuse and crime, not perpetrators of criminal activity as the media often portrays the mentally ill (Viday et al., 1999).

Mental illness is a prevalent disability that constitutes brain chemical imbalances leading to altered behaviors, mood imbalances, or sensory processing disorders that 1 in 4 people will develop in their lifetimes. From depression and anxiety to PTSD and schizophrenia, 1 in 5 Americans experience mental illness at a given time (NAMI, 2019b). This constitutes 43.8 million Americans each year, and $2.6 \%$ of U.S. adults are diagnosed and living with bipolar disorder at any given time (NAMI, 2019b).

But what does it mean to be bipolar? Formerly known as manic depression, bipolar disorder is characterized by the manic highs of elevated mood, irritability, impulsivity, and occasionally full-blown psychosis, hallucinations, and delusions (NAMI, 2019a). The other cyclical side of the spectrum is depression, characterized by loss of hope, appetite changes, sleep alterations, low mood and energy levels, and suicidal ideation or attempts. There are varying degrees of bipolar disorder, with Type 1 characterized by a full blown manic episode that lasts a qualifying amount of time and evidence of depressive episodes. Individuals with Type 2 bipolar do not experience full-blown mania. Bipolar Type 2 is defined as elevated hypomania that consists of grandiose opinions of the self, charisma, high energy and productivity, and strong drive to accomplish tasks alongside the lower moods of depression (NIH, 2018). Cyclothymia is the milder version of bipolar disorder, with lower highs of mild hypomania and softened edges of mild depression (American Psychiatric Association, 2002).

Bipolar disorder can be rapid cycling, with multiple manic or hypomanic episodes and depressions in a single year. More rarely, bipolar can create mixed episodes of depression and mania that often lead to suicide attempts or self-harm amongst bipolar individuals. In fact, 5.7 million American adults, or $2.6 \%$ of the American population, are bipolar (Doheny, 2019), indicating the prevalence of the disease. When bipolar is mentioned, celebrities with the prominent diagnoses of Robin Williams and Carrie Fisher usually come to mind. Williams and Fisher were two of the most famous celebrities who advocated for bipolar acceptance. The pair used the depths of their mental anguish to fuel inspirational acting roles and books about the disorder. In the end, Fisher and Williams achieved immortality in the public eye because in their suffering, they found the humor and inspiration to connect to generations of audiences.

But is bipolar disorder a death sentence and an unstable illness as the media portrays it? Or is there hope for individuals living with bipolar, a silver lining like in the Silver Linings Playbook?

With proper treatment, many great leaders of society thrive with bipolar disorder. Winston Churchill, Britain's heroic Prime
Minister during World War II, referred to his bipolar disorder as his "black dog" (Bipolar Lives, 2015). Kay Redfield Jamison, a prominent psychologist at Johns Hopkins University, wrote the seminal autobiography about bipolar disorder. Psychiatrists around the world recommend Jamison to their patients, with her novel An Unquiet Mind earning her critical acclaim.

Through diet, sleep, exercise, medication, and therapy, individuals with bipolar can thrive. In addition, with holistic treatments like yoga, meditation, and abstaining from drugs and alcohol, many individuals recover from the most distressing symptoms of the disorder and lead highly successful lives.

With determination, individuals with bipolar disorder leave such lasting marks on society that without their existence, the world would be devoid of Van Gogh's Starry Night, Isaac Newton's Calculus, the Shelley's poetry and books, and perhaps even Michelangelo's La Pieta or Da Vinci's Mona Lisa. These creative geniuses are all suspected by clinical psychologists to have been diagnosed with bipolar disorder, in a time before proper medication and therapy. With the preponderance of the diagnosis in everyone in history from Sylvia Plath to Hans Christian Anderson, the disorder is often called the "artist's disease," and many academic studies have linked bipolar disorder to creativity (Jamison, 1993).

In the modern day as well, individuals with bipolar disorder are oftentimes marked by creative genius. Many opinion leaders advocating reduction of stigma and promoting acceptance of bipolar disorder are actors, singers, entertainers, artists, politicians, authors, and athletes. Oftentimes, the strongest advocates such as Demi Lovato and Carrie Fisher have left not only a lasting mark on acceptance of mental illness, but also artistic legacies fueled by the disease's creative richness. Bipolar disorder, often, is a double-edged sword of creativity and instability, making it a rife field for study on the Wild West of social media. In the Twitter sphere, real-time advocacy and risk reduction of bipolar disorder is taking place daily amongst opinion leaders like Stephen Fry in the emerging field of ehealth communication.

The fulcrum of mental health advocacy happens each October and is gaining in popularity. World Mental Health Day is held annually every October 10th. The World Health Organization's definition of the holiday's purpose is "raising awareness of mental health issues around the world and mobilizing efforts in support of mental health. The Day provides an opportunity for all stakeholders working on mental health issues to talk about their work, and what more needs to be done to make mental health care a reality for people worldwide" (WHO, 2018).

After the recent death of actor Robin Williams by suicide in 2014 (Ghaemi, 2014) and the late Carrie Fisher's lifelong mental health battles with mania, depression, and substance abuse (Sarkis, 2016), awareness and stigma of bipolar disorder have overtaken the media as celebrity after celebrity has been revealed to have the disorder. This drives many celebrities with the diagnosis to become advocates for stigma reduction of bipolar disorder. World Mental Health Day during October 2018 was no exception, with celebrities sharing their own personal journeys with bipolar disorder and aiming to reduce stigma through advocacy and support. 
In 2018, it was not only revealed that pop sensation Mariah Carey had battled bipolar disorder her whole life (Bromwich, 2018), but Kanye West set off a media maelstrom when he made public his bipolar disorder diagnosis (Ali, 2018). West was hospitalized and entered what many would diagnose as full blown mania for months on end. His mania was marked by unhinged rants on Twitter, an uncomfortable performance on Saturday Night Live, and public appearances where he said such non-sensical statements as "slavery was a choice." West's mania culminated in him joining the Republican Party (he had been a lifelong Democrat and major donor of Clinton beforehand) and West's newfound friendship with Donald Trump. The unlikely pair's alliance culminated in an Oval Office visit where West advocated for mental health and criminal justice reform.

With bipolar celebrities like West in the spotlight in 2018, World Mental Health Day was a sensation in October of 2018. The hashtag \#WorldMentalHealthDay trended on international social media and platforms like Facebook and Twitter. Many celebrities made posts about their own struggles with mental illness and bipolar disorder specifically, which pose serious health risks as 1 in 5 Americans will develop a mental illness in a given year (NAMI, 2018). Opinion leaders called for increased risk communication and risk reduction strategies surrounding the disorder in the form of advocacy and support. One of the celebrities to lead the charge was singer Demi Lovato, who has championed mental health awareness ever since she was diagnosed with bipolar disorder in 2011 (Greer, 2015).

Mood disorders like bipolar and major depression are the third most common causes of hospitalization in the United States for youths and adults aged 18-44 (NAMI, 2018). This poses a serious risk to health where the most dangerous symptom of bipolar disorder is the high suicide rate (Kessing et al., 2015). Up to $60 \%$ of individuals with bipolar disorder attempt to commit suicide and $19 \%$ of those succeed, a terribly high mortality rate. This signifies how deadly the disease is and marks a clear need for risk reduction strategies amongst patients (Novick et al., 2010).

Reducing mental health stigma is a form of risk management, and awareness campaigns are part of the solution to the health risks of mental illnesses. No time is more popular for mental health advocacy than World Mental Health Day. With the public, private sector, and opinion leaders holding stakes in advocacy on October 10th, nothing speaks louder than opinion leaders like celebrities. Celebrities advocating for change in the way society treats mental illness, bipolar in particular, and encouraging sufferers to seek treatment, can effect great change on how the public perceives mental illness and bipolar in particular.

Opinion leaders following the tenets of Everett Rogers' diffusion of innovation model in health communication are key leaders in spearheading lasting health changes, Often, opinion leaders possess large platforms or high social status like being celebrities or spokespeople (Rogers, 2002). In fact, celebrities (like Carrie Fisher) speaking and writing novels about their experiences with bipolar disorder fosters feelings of camaraderie and fellowship with readers and viewers, This means individuals confronting these mental health problems feel less alone, giving them a sense of kinship to opinion leaders experiencing the same challenges as them. This fosters hope in individuals with bipolar disorder and serves as inspiration to recover and thrive.

But how does the advocacy of opinion leaders about the framing of bipolar disorder relate to risk? Risk communication is often defined as "the process of conveying to interested parties the outputs of the various stages of risk analysis and risk management" (Fiksel and Covello, 1987). Following Katherine Rowan's CAUSE model of risk communication (Rowan, 1991; Rowan et al., 2017), this study examines social media posts issued on World Mental Health Day by examining the extent to which their goals are consistent with the A in the CAUSE model, creating Awareness, the $\mathrm{U}$, which focuses on deepening Understanding, and finally the $\mathrm{E}$, which encourages people to move from agreement that something is important to taking steps to Enact change.

The CAUSE model is a model of risk communication developed by Dr. Katherine Rowan in 1991 that aims to ameliorate the dangers of risk to the public through five avenues, or steps. This includes creating Confidence in the public in risk communicators and opinion leaders, increasing Awareness of the risk to society, engendering Understanding of the risk to create reduction and preparedness strategies amongst laypeople, fostering Satisfaction in taking actions to prevent danger and hence feel informed about risk reduction decisions, and finally, creating Enactment of policy changes supported by the public that ultimately reduce or eliminate the risk posed, like the law requirement to wear seatbelts. When applied to a health communication context, the CAUSE model of risk communication seeks to establish Awareness about health risks, including best strategies to cope with or heal from illness or disability, Satisfaction with medical treatment and public reception, and ultimately, systematic policy changes in healthcare that Enact best care practices for the sick, chronically ill, or disabled.

Other tangential goals under the CAUSE model in this study are the $\mathrm{C}$, creating Confidence in communicators, or in this case, opinion leaders. Less related is the $S$, fostering Satisfaction in mental health reform and messages and reduced stigma. Overall, society is still far from pro-neurodivergent narratives and frames in the media, corporations, health fields, and government. Otherwise World Mental Health Day would no longer be necessary if mental illness did not carry negative associations and dangerous stereotypes when conjured in the public's mind. For example, when mass shootings occur, the first question that comes up in public dialogue is the state of the shooter's mind and if they have a history of mental illness.

To this day, in American culture and the majority of the world at large, being labeled mentally ill is the most stigmatized condition an individual can go through. This diagnosis is coupled with lack of societal support and the dominant narrative of mental illness as that of the serial killer or mass shooters. This causes frustration, the lack of Satisfaction. It is an ultimate goal of World Mental Health Day and mental health reform to foster a sense of Satisfaction with the public's mental health understanding and portrayal.

Opinion leaders diagnosed with bipolar disorder and advocating for mental health reform have already earned the 
Confidence of their audiences, and as a whole, society is far from the Enactment phase of the CAUSE model, still focusing on deepening Understanding and creating Awareness. Mental health reform is still very new to society and in the exploratory stages of diffusion of innovation. Hence, in my analysis, I focus on the $\mathrm{A}$ and the $\mathrm{U}$, with predictions about $\mathrm{E}$ and implications of Enactment as the ultimate result of mental health advocacy.

Opinion leaders are well-suited to be the drivers of change in all three of these CAUSE areas. This study reports a content analysis of social media posts from World Mental Health Day across Facebook, Twitter, and Instagram from a pool of randomly selected celebrities diagnosed with bipolar disorder. It investigates what content themes emerge, how the terminology around bipolar and mental health in general is framed, the public's reaction to opinion leader's posts, and whether opinion leader posts follow the CAUSE model of risk communication to motivate Enactment, create Awareness, and gain Understanding.

Seminal communication scholar Brant R. Burleson inferable communication goals in his extensive work on emotional support as forms of comfort (Burleson et al., 1996) was utilized to code opinion leaders' tweets into four inferable goals: encouragement, affirmation of one's values, comfort to others, criticism of others, and a fifth category of neutral tweets. Burleson and his predecessors have proven that encouraging, affirming, emotionsbased expressions of comfort are strong ways to convey social support across gender and cultural divides. Burleson's work has been heavily cited by scholars and applied to interpersonal communication as one of the bases for effective compassionate communication (Burleson and Mortenson, 2003). Applied to a health context, encouraging social support helps demystify how opinion leader's actions make the public feel less stigmatized in areas such as disability or illness. Emotional support is at the core of mental health recovery, and encouragement to persevere is of tantamount importance among the mentally ill's social networks under Burleson's framework.

\section{Research Questions and Hypothesis}

My hypotheses for this study are:

$\mathrm{H} 1$ : Opinion leaders will advocate for mental health stigma reduction and reform with overall positive valences to their tweets.

$\mathrm{H} 2$ : Overall, positive messages of encouragement, affirmation of one's values, and comfort to others will dominate opinion leaders' Tweets on World Mental Health Day

H3: A month after the initial tweets, advocacy and mental health reduction tweets will be the major content trend amongst the general public.

R1: Where under the framework of Rowan's CAUSE Model of risk communication do illustrative opinion leader Tweets fall on World Mental Health Day in promoting Awareness and Understanding?

\section{MATERIALS AND METHODS}

The study in question adhered to applicable institutional and national guidelines and regulations regarding not requiring ethics approval by the IRB.
A purposive sample was gathered randomly of the first 160 opinion leaders most prevalent in a simple Google search of "celebrities with bipolar disorder," referencing the first top lists of prominent living celebrities with bipolar disorder yielded by the Google search. Also included were individuals with the most popular Google results for "celebrities with bipolar disorder" in numerical order until a sample of statistical significance was reached. Opinion leaders were counted as celebrities with large social media platforms including musicians, actors, directors, authors, politicians, and athletes who were all officially diagnosed with bipolar disorder. Those not officially diagnosed with bipolar disorder were not included.

Tweets on October 10th, 2018 were analyzed for mentions of positive or negative framing of mental health (Supplementary Table 1). They were sorted into valences of 1 for negative associations, 2 for neutral, and 3 for positive. For example, valences that constituted negative associations referenced addiction, suicide, hopelessness, and despair. Valences that constituted normal activities, balanced emotions surrounding activity, and anything that took neither side were neutral. Positive valences discussed encouragement, recovery stories, themes of healing, and advice and help for those who were struggling with bipolar disorder.

The \#WorldMentalHealthDay hashtag was used in analysis. Overall, of the 160 twitter accounts surveyed, only 47 accounts were active and tweeted at least once on October 10th. This led to a sample of 88 tweets to analyze. Data analysis tracked likes, responses, and retweets to analyze the popularity and permeation of the idea down the diffusion of innovation chain from early adopters onwards.

Tweets were then coded for inferable communication goals from the CAUSE model as well as emotional support goals identified by Burleson and colleagues including: (1) affirmation of someone's inherent value, (2) comfort to others, (3) encouragement to others, and (4) criticism of others (Burleson et al., 1996).

For thematic analysis, I first drew upon Rowan's CAUSE Model of Risk Communication. I categorized themes of celebrity tweets into the five different CAUSE categories. I analyzed the tweets to find common strands of messaging and framing under the concentrated umbrellas of Awareness and Understanding to see how these themes were worded and to what effect of risk management and reduction, with other categories also noted but not as prevalent.

Also guiding the thematic analysis was Burleson's guidelines of emotional support and compassionate encouragement. This built upon the positive valences detected in Tweets and inferable communication goals of opinion leaders. I analyzed for the content of positively valenced messages to find what themes of treatment, awareness, narrative sharing, and support were communicated in celebrity Tweets under Burleson's framing guidelines. These have all been shown in Burleson's body of work to increase positive health outcomes and hence guided my extensive analysis.

These tweets were cross-compared to a census sample of all tweets covering the entire Twitter population with the hashtags \#bipolar and \#bipolardisorder charting a week in November 


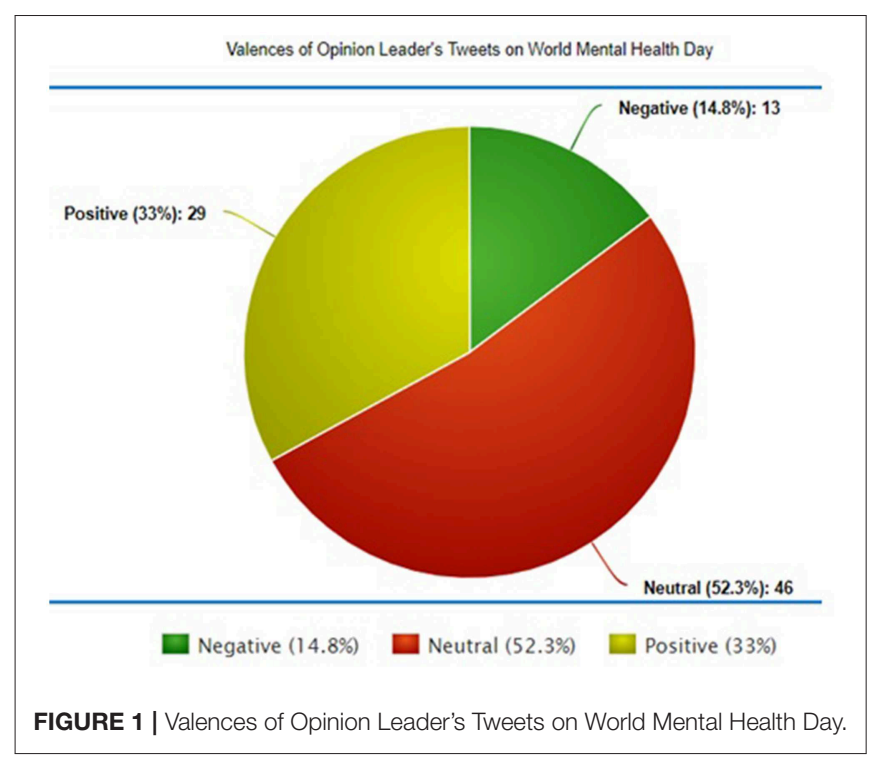

exactly a month after October 10th, 2018. DiscoverText was used to create API feeds amassing all tweets with two feeds, one for \#bipolar and one for \#bipolardisorder. In all, over the course of seven days, a total of 3,288 tweets were amassed in the DiscoverText archive: 2,845 for the hashtag \#bipolar, and 703 for \#bipolardisorder.

\section{Results}

Across the board, opinion leaders who tweeted on World Mental Health Day framed bipolar disorder in a positive light, with an exact third, 33\% (Figure 1), framing their Tweets in a positive valence with themes of encouragement $(21.6 \%$ of tweets), affirmation of positive values (9.1\% of tweets), and comfort to others, (3.4\% of tweets), with a total positive framing of communication goals again an approximate third (34.1\%) of the tweets sampled communicating positively valenced, stigma reducing and encouraging inferable communication goals (Figure 2). Tweets were gathered from 160 opinion leaders officially diagnosed with bipolar disorder type 1 or 2 on World Mental Health Day and coded for 1 of 4 inferable communication goals and assigned valences to gather this data. This fits in with research Hypothesis 1: that overall, opinion leaders will advocate for mental health stigma reduction and reform with overall positive valences to their tweets.

On the negatively valenced side, a minority of tweets with a mental health message, $14.8 \%$, were cast in a negative light, with only $13.6 \%$ of total tweets containing criticism of others in mental health such as bad behavior caused by mental disorders, suicide, and hopelessness as inferable communication goals. As for tweets that were neutral, including a majority that were not about mental health, about half $(52.3 \%)$ of tweets were not about mental health on October 10th, 2018 among the 160 opinion leaders sampled, while approximately another half were aligned with mental health messaging (47.8\%). This demonstrated that approximately 1 in 2 opinion leaders diagnosed with bipolar disorder chose to Tweet about mental health in a mostly positively framed way on World Mental Health Day, if they Tweeted on that day at all. The greatest inferable communication goal amongst opinion leaders was encouragement to others for mental health recovery, struggle, and treatment. This is in line with Hypothesis 2: Overall, positive messages of encouragement, affirmation of one's values, and comfort to others will dominate opinion leaders' Tweets on World Mental Health Day

A month later, from a Twitter census of the \#bipolar and \#bipolardisorder hashtags that lasted a week exactly a month after World Mental Health Day occurred and surveyed the entire Twitter population, a theme of positive framing around bipolar disorder emerged. From the top themes found in the \#bipolar hashtag, 75 (50\%) were neutrally valenced, and of those that carried valences, 54 (36\%) were positively valenced, and only $19(12.67 \%)$ were negatively valenced (Figure 3). In the \#bipolardisorder hashtag, 75 themes (50\%) were neutrally valenced, $52(34.67 \%)$ were positively valenced, and only 22 $(14.67 \%)$ were negatively valenced (Figure 4$)$. The thematic values across the \#bipolar and \#bipolardisorder hashtags are almost equal, underlying the robustness of the positive themes' consistent messaging amongst the general Twitter populace a month after World Mental Health Day and a positive valence overall in the hashtags. This justifies Hypothesis 3: A month after the initial tweets, advocacy and mental health reduction tweets will be the major content trend amongst the general public (Figures A1, A2).

Deducing the framing of the inferable communication goals of opinion leaders on World Mental Health Day was straightforward under Burleson's guideline. The positively valenced tweets amongst celebrities either communicated encouragement, affirmation of one's values, or comfort to others in descending order. Negatively valenced tweets were in the minority, containing criticism of others.

\section{IMPLICATIONS AND RECOMMENDATIONS}

Overall, opinion leaders overwhelming communicated positively about themes of recovery, comfort, and hope on World Mental Health day. This reduces mental health risks of the very real threats of isolation bipolar individuals can feel when no one in the media speaks to destigmatize their condition and the hopelessness and violence portrayed in messages about mental health in the media. About a quarter of the Tweets had the inferable communication goal of encouragement, and over a third were positively valenced. This study provides proof that diffusion of innovation is actively occurring on social media amongst celebrity opinion leaders, on Twitter specifically, to normalize bipolar disorder and combat mental health stigma.

Following Rowan's CAUSE model of risk communication, the majority of opinion leader's tweets on October 10th sought to Enact Awareness and Increase Understanding under the framework of mental health risk reduction. Stigma is a great reason for the risks associated with mental health. Bipolar disorder portrayal specifically, where many people hold prejudices against the mentally ill and stigmatize bipolar disorder, leads to abuse, decreased quality of life, depleted happiness, job 


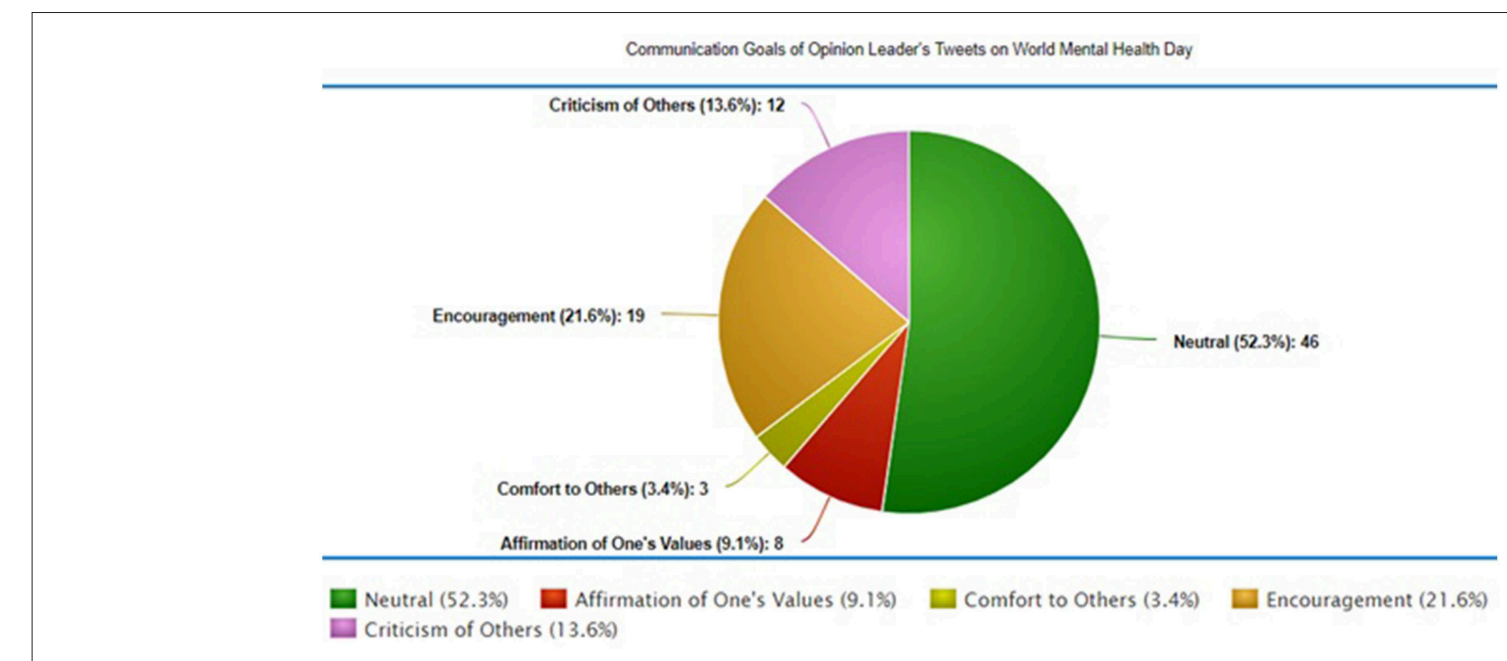

FIGURE 2 | Communication Goals of Opinion Leader's Tweets on World Mental Health Day.

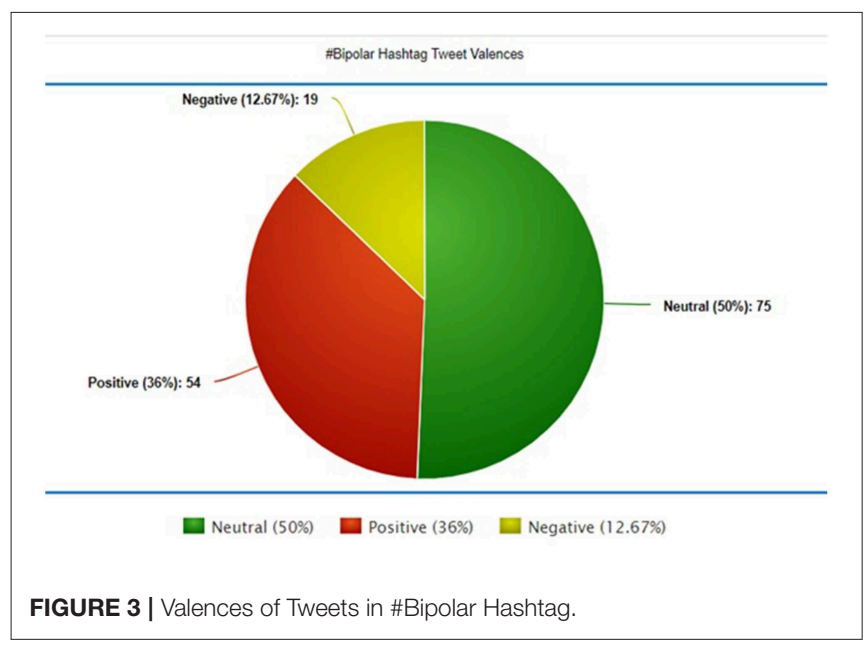

and relationship discrimination, and prejudice from family and friends in individuals with bipolar disorder. The way the media frames the narrative surrounding bipolar disorder, especially celebrities diagnosed with bipolar disorder that constituted my network of 160 purposively sampled opinion leaders, can shift the conversations surrounding bipolar disorder to one of risk reduction, recovery, encouragement, comfort, and positive valences overall.

Exactly a month after World Mental Health Day topped Twitter's trending hashtags, a weeklong census of the entire population of Twitter users in the \#bipolar and \#bipolardisorder hashtag indicated an influence of positive framing, The study revealed overwhelmingly encouraging, stigma reducing, and mental health awareness themes in thematic analysis. There was also a minimization of hopelessness, despair, and negative valences in line with opinion leader's small percentage of negative framing of bipolar disorder.

This thematic and contextual analysis of the Twitter universe of mental health dialogues surrounding bipolar disorder combats

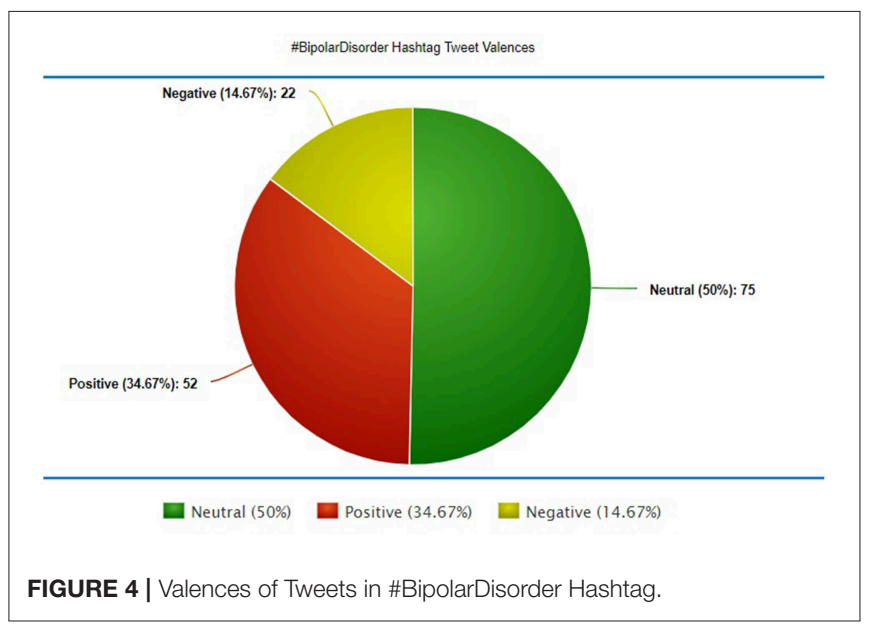

the negative framing in the media of bipolar disorder. Instead, it reveals a positive frame shift in social media users across Twitter highly encouraged by bipolar opinion leaders that serves as inspiration for other diagnosed bipolar individuals to recover, thrive, and prosper.

This natural growth in positive messaging, inferable mental health communication goals of comfort and encouragement, and overall positive valences in opinion leaders and the general public surrounding mental health stigma, in this case bipolar, indicates a frame shift in the framing of bipolar disorder. To encourage tailored messaging that resonates with the audience, bipolar advocates could use messages that advocate comfort and encouragement as opposed to affirmations of values and criticism when crafting targeted risk reduction mental health messages.

This study serves to guide future explorations of the frame shift occurring in the bipolar community and social media universe at large. It confirms my hypothesis that a month after World Mental Health Day broke records across social media, the general populace would maintain overall positive framing of bipolar disorder and positively valenced themes surrounding 
recovery, survival, and treatment first voiced by opinion leaders on the holiday.

As for diffusion of innovation and resonance with the entire Twitter populace, the most prominent opinion leader's Tweets officially diagnosed with bipolar disorder on October 10, 2018 were liked an average of 2481.36 times, retweeted an average of 487 times, and garnered a response rate of 57.78 comments per tweet. Overall, across the board of the 160 opinion leaders Tweet's, there was a total of 5,027 responses, 215,902 likes, and 42,384 retweets. This shows a significant population of Twitter users engaged with mental health messaging on World Mental Health Day, responding to it enough to trend the Tweets and hashtag, \#WorldMentalHealthDay, to the top of trending hashtags on Twitter on October 10th, 2018. This was greatly in part due to opinion leader's participation.

Overall, following Roger's diffusion of innovation theory, opinion leaders are modeling systematic communication tactics to change the dialogue surrounding mental health stigma from negativity toward stigma reduction and acceptance of neurodivergence. This makes for more positively valenced dialogue surrounding bipolar disorder communication, specifically in the general populace. The positive framing lasted a month after the opinion leaders communicated support, comfort and encouragement under Burleson's inferable communication goals on World Mental Health Day.

The mainly positive and neutrally valenced census sample tweets of the general populace on Twitter in the \#bipolar and \#bipolardisorder hashtags a month later demonstrates that the innovation opinion leaders advocated of positive mental health messages has now spread to the general populace. This occurred through opinion leaders' consistent messaging in awareness campaigns that opinion leaders diagnosed with bipolar disorder spearheaded on World Mental Health Day. The celebrities effectively shifted the conversation surrounding bipolar disorder on social media toward one of support, acceptance, and positivity.

Via the aforementioned analysis of Tweets in the Twitter census conducted a calendar week after World Mental Health Day, there was an overwhelming majority of themes either positively or neutrally valenced in the \#bipolar and \#bipolardisorder hashtags. It would appear that the dialogue surrounding bipolar disorder, led by opinion leaders, has now penetrated society with the innovation of positive messages about bipolar disorder adopted by the majority of the Twitter populace. This puts the innovation at the late majority stage of Roger's adoption profile, with $<16 \%$ of Twitter users utilizing the \#bipolar and \#bipolardisorder hashtags to communicate negatively valenced messages.

This study was limited in several ways, a major factor being that many celebrities are not open about their bipolar disorder or lacking diagnoses. Because of the severe reluctance to admit diagnoses of bipolar disorder, we are missing dozens if not hundreds of opinion leaders with undiagnosed or undercover bipolar disorder, like how Mariah Carey kept her illness hidden from the public for over 20 years of stardom. Themes of shame and regret are very strong amongst bipolar individuals, causing many opinion leaders to choose not to take an advocacy position on World Mental Health Day and even keep their diagnoses close to their chests for fear of rejection or career damage.

A major limitation of content analysis is that I could not precisely examine the reasons for the ways people communicate, so future research would involve qualitative interviews with some of the celebrities who Tweeted to find out why they wrote what they did on World Mental Health Day and how they hoped their Tweets would influence others. For future research and advocacy, public health researchers focused on mental health could work alongside opinion leader spokespeople like Demi Lovato or Stephen Fry to advocate reducing stigma and the theme that resonated most: positively valenced Tweets about encouragement.

Message targeting to youths, who are the most vulnerable to mental illness, on popular social media sites like Instagram and Snapchat would reach an even wider audience. If a concerted pool of opinion leaders had unified messages of encouragement, comfort, and value-based hope on World Mental Health Day, including opinion leaders like Kanye West who advocate for mental health reform on days other than October 10th but did not tweet about bipolar disorder on the designated holiday, the diffusion of reducing mental health stigma would greatly increase. Strength lies in numbers, and with more opinion leaders advocating emotional support of bipolar disorder on World Mental Health Day, the world could see real change in the stigma surrounding the disorder and a lasting frame shift toward understanding and acceptance. More importantly, those that suffer would know they were not alone, and would be encouraged to take positive steps toward treatment and recovery.

\section{AUTHOR CONTRIBUTIONS}

This was an individually conducted project and all data collection, hypothesizing, and analysis were carried out by AN.

\section{ACKNOWLEDGMENTS}

I owe a debt of gratitude to Dr. Gary Kreps and Dr. Katherine Rowan for their support during this study, measured wisdom in guiding my analysis, and depth of knowledge and passion for health and risk communication. I stand on the shoulders of giants in the field.

\section{SUPPLEMENTARY MATERIAL}

The Supplementary Material for this article can be found online at: https://www.frontiersin.org/articles/10.3389/fcomm. 2019.00024/full\#supplementary-material

Supplementary Table 1 | Opinion Leader Tweets on World Mental Health Day. 


\section{REFERENCES}

Ali, S. (2018). Can Kanye West Promote Mental Health Awareness? Psychology Today. Retrieved from: https://www.psychologytoday.com/ us/blog/modern-mentality/201805/can-kanye-west-promote-mental-healthawareness (accessed January 7, 2019).

American Psychiatric Association (2002). Practice Guideline for the Treatment of Patients With Bipolar Disorder, Vol. 159. Washington, DC: American Psychiatric Association.

Bipolar Lives (2015). Winston Churchill and Manic Depression. Retrieved from: https://www.bipolar-lives.com/winston-churchill-and-manicdepression.html

Bromwich, J. (2018). Mariah Carey Opens Up About Bipolar Disorder. The New York Times. Retrieved from: https://www.nytimes.com/2018/04/11/style/ mariah-carey-bipolar-disorder.html

Burleson, B., Kunkel, A., Samter, W., and Working, K. (1996). Men's and women's evaluations of communication skills in personal relationships: when sex differences make a difference and when they don't. J. Soc. Pers. Relation. $13: 2$.

Burleson, B., and Mortenson, S. (2003). Explaining cultural differences in evaluations of emotional support behaviors: exploring the mediating influences of value systems and interaction goals. Commun. Res. 30:2. doi: 10.1177/ 0093650202250873

Doheny, K. (2019). 8 Myths About Bipolar Disorder. WebMD. Retrieved from: https://www.webmd.com/bipolar-disorder/features/8-myths-aboutbipolar-disorder\#1

Fiksel, J., and Covello, V. (1987). Expert systems and knowledge systems for risk communication. Environ. Prof. 9, 144-152.

Ghaemi, N. (2014). Not "Depression:" Manic-Depression and Robin Williams. Psychology Today. Retrieved from: https://www.psychologytoday.com/us/ blog/mood-swings/201408/not-depression-manic-depression-and-robinwilliams

Greer, J. (2015). Demi Lovato: How Do You Overcome Depression? New York, NY: Psychology Today.

Jamison, K. R. (1993). Touched With Fire: Manic-Depressive Illness and the Artistic Temperament. New York, NY: Free Press.

Kessing, L. V., Vradi, E., and Andersen, P. (2015). Life expectancy in bipolar disorder. Bipolar Disorders 17, 543-548.

NAMI (2018). Mental Health by the Numbers. National Alliance on Mental Illness. Retrieved from: https://www.nami.org/Learn-More/Mental-HealthBy-the-Numbers
NAMI (2019a). Bipolar Disorder. National Alliance on Mental Illness. Retrieved from: https://www.nami.org/learn-more/mental-health-conditions/ bipolar-disorder (accessed January 7, 2019).

NAMI (2019b). Mental Health by the Numbers. National Alliance on Mental Illness. Retrieved from: https://www.nami.org/learn-more/mental-health-bythe-numbers

NIH (2018). National Institute of Health. Retrieved from: https://www.nimh.nih. gov/health/topics/bipolar-disorder/index.shtml (accessed January 7, 2019).

Novick, D. M., Swartz, H., and Frank, E. (2010). Suicide attempts in bipolar I and bipolar II disorder: a review and meta-analysis of the evidence. Bipolar Disord. 12, 1-9. doi: 10.1111/j.1399-5618.2009.00786.x

Rogers, E. (2002). Diffusion of preventive innovations. Addict. Behav. 27, 989-993. doi: 10.1016/S0306-4603(02)00300-3

Rowan, K. (1991). Goals, obstacles, and strategies in risk communication: a problem-solving approach to improving communication about risks. J. Appl. Commun. Res. 19, 300-329.

Rowan, K. E., Engblom, A., Hathaway, J., Lloyd, R., Engblom, A., Vorster, I., et al. (2017). "Science communication as strategic communication: Applying the CAUSE Model to communicate climate change," in The International Handbook of Strategic Communication, ed C. H. Botan (New York, NY: WileyBlackwell), 1-33.

Sarkis, S. (2016). Why We Owe Carrie Fisher a Debt of Gratitude. Psychology Today. Retrieved from: https:/www.psychologytoday.com/us/blog/herethere-and-everywhere/201612/why-we-owe-carrie-fisher-debt-gratitude (accessed January 7, 2019).

Viday, V. A., Swartz, M. S., Swanson, J. W., Borum, R., and Wagner, H. R. (1999). Criminal victimizations of persons with severe mental illness. Psychiatr. Serv. $50,62-68$.

WHO (2018). World Health Organization World Mental Health Day - 10 October. Retrieved from: http://www.who.int/mental_health/world-mental-health-day/ en/ (accessed January 7, 2019).

Conflict of Interest Statement: The author declares that the research was conducted in the absence of any commercial or financial relationships that could be construed as a potential conflict of interest.

Copyright (C) 2019 Nelson. This is an open-access article distributed under the terms of the Creative Commons Attribution License (CC BY). The use, distribution or reproduction in other forums is permitted, provided the original author $(s)$ and the copyright owner(s) are credited and that the original publication in this journal is cited, in accordance with accepted academic practice. No use, distribution or reproduction is permitted which does not comply with these terms. 


\section{APPENDIX}

able access actuallyautistic addiction adhd aims amazon amwriting anxieties anxiety associated bear bears bekalombardo believe $\mathrm{O} / \mathrm{O}$ bipolarbattle bipolardisorder bipolarwarrior blog bloggerstr bloggerstri blogpost blogspot borderline bpd brain cannabis cant check clownandi comedian comic competent counseling day days depressed depression depressionisreal disorder disorders dont easy electroboyusa else endableismnow endthestigma feel fix fragments friends funny gifts god guide happy health help highs hope humor ii illness improve improved including intense intlbipolar journey julietteburton keeptalkingmh kulikovuniatf life link lithium little living lost love Itcartoons madddawgdailey manages mania manic meds mental

mentalhealth mentalhealthawareness mentalhealthmatters mentalillness mhap mhblogfam mhchat mhsm mind mjnews mo mood nrmentalhealth ocd own parent patients people person phenomenal physical please podcast post psychiatry psychosis ptsd quickest recovery resistancerises role rosecmanalo1 schizoaffective schizophrenia selfcare services shit sicknotweak skinnyfabulous sometimes starfish72 stigma story stress struggling suicide suicideprevention

support survi talks tell thanks therapy time times treatment trying type vixxyrose wordpress write writer yourself

FIGURE A1 | \#Bipolar Hashtag Cloud of Census Tweets.

able adhd ago anxiety article ashamed assistant author believe believes

bipolar bipolar2 bipolarbattle bipolardepression

bipolardisorder

bpd bpdmanicbir buy cant check comments common condition conocidos consequences copy creer cuenta dado day days deambulas defined demon depressed depression depressionisreal depressive dices disorder doctor dont dyaneharwood eleanorsegall endthestigma energy enjoy entire entre episode estás excited experience family feel forma friends grateful happifulhq happy health help hope hospital ich ill illness impacted intlbipolar job keeptalkingmh life link lithium little live living looking lot love mania manic

mayahez medication mental mentalhealth mentalhealthawareness mentalhealthmatters mentalillness mind minimizing monday month months moods nada nadia ni normal otherwise people peor person phd please post pregnancy psychiatrist psychreg ptsd qimrberghofer read recovery recoverybd recruiting research schizophrenia sibleyh sicknotweak spectrumcentre stage stigma stop story study suicide suicideprevention support symptoms talk te tell thank therapy time told treatment try tus vivir vivo week weeks write youre

FIGURE A2 | \#BipolarDisorder Hashtag Cloud of Census Tweets. 